\title{
BMJ Open A cross-sectional analysis of the relationship between diabetes and health access barriers in an urban First Nations population in Canada
}

\author{
Michael Beckett, ${ }^{1}$ Michelle A Firestone, ${ }^{2,3}$ Constance D McKnight, ${ }^{4}$ Janet Smylie, ${ }^{2,3}$ \\ Michael A Rotondi ${ }^{1}$
}

To cite: Beckett M,

Firestone MA, McKnight CD, et al. A cross-sectional analysis of the relationship between diabetes and health access barriers in an urban First Nations population in Canada. BMJ Open 2018;8:e018272. doi:10.1136/ bmjopen-2017-018272

- Prepublication history and additional material for this paper are available online. To view these files, please visit the journal online (http://dx.doi. org/10.1136/bmjopen-2017018272).

Received 16 June 2017 Revised 25 August 2017 Accepted 15 September 2017

\section{Check for updates}

${ }^{1}$ School of Kinesiology and Health Science, York University, Toronto, Ontario, Canada ${ }^{2}$ Well Living House, Centre for Research on Inner City Health, Li Ka Shing Knowledge Institute, St. Michael's Hospital, Toronto, Ontario, Canada

${ }^{3}$ Dalla Lana School of Public Health, University of Toronto, Toronto, Ontario, Canada ${ }^{4}$ De dwa da dehs nye $>$ s Aboriginal Health Centre, Hamilton, Ontario, Canada

Correspondence to

Michael Beckett;

mwtb@yorku.ca

\section{ABSTRACT}

Objective This study explores the relationship between health access barriers and diabetes in an urban First Nations population in Canada.

Design Data from a self-identified urban First Nations population were collected using respondent-driven sampling (RDS). As no clear approach for regression modelling of RDS data is available, two logistic regression modelling approaches, including survey-based logistic and generalised linear mixed models, were used to explore the relationship between diabetes and health barriers of interest, including access to healthcare, food, housing and socioeconomic factors.

Setting Hamilton, Ontario, Canada.

Participants This cross-sectional study used data collected from the Our Health Counts study, in partnership with the De dwa da dehs nye>s Aboriginal Health Centre, which recruited 554 First Nations adults living in Hamilton using RDS.

Results After adjusting for covariates, multivariable regression techniques showed a statistically significant relationship between a self-reported diagnosis of diabetes and a lack of culturally appropriate care among urban First Nations peoples (OR: $12.70,95 \% \mathrm{Cl} 2.52$ to 57.91 ). There was also a trend towards a relationship between diabetes and not having a doctor available in the area, feeling that healthcare provided was inadequate and a lack of available healthcare services in the area.

Conclusions Urban First Nations peoples who felt the health service they received was not culturally appropriate were more likely to have diabetes, compared with those who did not feel the service they received was culturally inappropriate. Establishing more healthcare services that integrate First Nations cultures and traditions could improve access to care and the course of treatment for urban First Nations peoples living with diabetes.

\section{INTRODUCTION}

According to 2006 census data, a larger proportion of First Nations peoples are living off reserves than on reserves in Canada, with approximately $76 \%$ of the off-reserve population living in an urban area. ${ }^{1}$ First Nations peoples, along with Inuit and Métis peoples,

\section{Strengths and limitations of this study}

- This paper used data that were collected through respondent-driven sampling (RDS), which provides a representative sample of an urban First Nations population.

- This paper is one of the first to explore health access barriers among First Nations peoples living in an urban environment, a group for which populationbased health data are otherwise not readily available.

- The data used for the analysis in this paper were collected using a community-based participatory approach, ensuring Indigenous partners were active in every step of data collection and dissemination.

- Multivariable analysis methods for analysing data collected through RDS have not been fully validated, so this paper explores the results of two different modelling approaches.

make up the three Indigenous ${ }^{\mathrm{i}}$ groups recognised by the Canadian census. ${ }^{2}$ First Nations peoples were historically forcefully removed from their traditional lands onto federally government owned 'reserve lands' as part of early colonial efforts to eradicate the First Nations culture and force their assimilation into Euro-Canadian society. ${ }^{34}$ Despite this, the First Nations peoples in Canada have demonstrated remarkable resiliency, and today there are over 600 First Nations communities in Canada constituting more than 60 First Nations languages. ${ }^{2}$

\footnotetext{
${ }^{\mathrm{i}}$ The Constitution Act of 1982 specifies the term Aboriginal peoples as the collective name for three groups of peoples in Canada: Indians, Inuit and Métis. The term Indigenous is increasingly being used in lieu of the term Aboriginal as it is more relevant, inclusive and does not stem from federal government legislation. The term First Nations came into use in the 1970s to replace the term Indian, which some people found offensive. Currently there is no legal definition for the term First Nations in Canada.
} 
First Nations peoples began migrating to urban areas in 1951, when a law prohibiting the free movement off reserves for First Nations peoples was formally repealed. ${ }^{4}$ Many First Nations peoples migrate to urban areas to seek better housing, educational or employment opportunities, or improved access to healthcare services. ${ }^{5-7}$ While the migration of First Nations peoples to urban areas has been occurring for multiple generations, there has been exponential growth more recently in the urban First Nations population. Between 1996 and 2006 the urban First Nations population increased in size by $29 \% .^{1}$ This rapid growth can partially be explained by demographic changes in how urban First Nations peoples choose to self-identify on the census. ${ }^{1}$ This phenomenon of changing one's ethnic affiliation on the census over time, called ethnic mobility, coupled with a birth rate that is 1.5 times higher than the non-First Nations birth rate in Canada, has contributed to this recent rapid population increase. $^{7-9}$

Despite the growing population of First Nations peoples living in urban areas, health data on this population are sparse. Health research in Canada has focused primarily on First Nations peoples living on reserves, and even when included in national surveys, urban First Nations peoples are routinely undercounted. ${ }^{10} 11$ For example, the Canadian Community Health Survey (CCHS), which excludes First Nations peoples living on reserves, fails to enumerate Indigenous sample population numbers high enough to disaggregate data specific for each of the Indigenous subgroups (ie, data specific to First Nations, Inuit or Métis peoples) beyond a provincial level. ${ }^{11}$ The inability to isolate meaningful health data for First Nations peoples is problematic given the number of persistent inequities in health status and unique health challenges incurred by each of the on-reserve and off-reserve populations. ${ }^{712}$

One of the major health challenges affecting the First Nations population in Canada is diabetes, which has reached epidemic-level proportions in this population. ${ }^{13}$ National data indicate the age-adjusted prevalence of diabetes is three to five times higher among First Nations peoples compared with the general population. ${ }^{14}$ This prevalence varies regionally, with higher rates found among First Nations populations closer to urban centres. ${ }^{13}$ Circulatory diseases are the most common cause of death for adult Indigenous peoples living in urban areas, ${ }^{7}$ and 2009/2010 CCHS data indicate that prevalence of diabetes is twice as high among First Nations peoples living off reserve, compared with the non-Indigenous population. ${ }^{15}$ In addition to a higher prevalence of diabetes, First Nations people in Canada are more likely to be diagnosed with diabetes at a younger age and suffer from a higher rate of diabetes-related comorbidities. ${ }^{16}$ The large number of health disparities in the First Nations population can be traced to the effects of European colonisation, where the First Nations peoples suffered abuse, forced relocation and cultural suppression. The effects of colonisation have had a lasting impact on First Nations people's sense of self and well-being and placed them at a point of social and economic disadvantage, resulting in higher rates of poverty, food insecurity and a poorer health status overall. ${ }^{516} 17$ Poverty, along with a lack of access to nutritional foods and the adoption of the more sedentary Western lifestyle, has contributed to the increasing prevalence of diabetes among the First Nations population. ${ }^{17}$

The increased prevalence of diabetes and related comorbidities observed in this population is further exacerbated by a lack of equitable access to preventative and primary healthcare services. ${ }^{16}$ Preventative health services have the potential to target individual risk factors for diabetes, including social and economic factors, to prevent the onset of diabetes. ${ }^{16}$ Despite a closer proximity to health services, First Nations peoples in urban areas still incur substantial barriers to equitable care, including discrimination, discrepancies in eligibility for federally funded health benefits and lack of access to culturally appropriate services. ${ }^{31518}$ To date, little evidence is available on the influence of these barriers on the health status of urban First Nations peoples in Canada. ${ }^{3}$

The purpose of this paper is to explore the relationship between different health access barriers and diabetes among an urban First Nations group living in Hamilton, Ontario, Canada, while adjusting for covariates, including age, sex, body mass index (BMI), physical activity levels, alcohol consumption and smoking status. Data were obtained from a sample of urban First Nations people, collected through the Our Health Counts (OHC) study, which used respondent-driven sampling (RDS) to recruit study participants. Statistical methods for analysing data collected through RDS have not been validated; therefore, this paper compares the results of two potential statistical approaches for the multivariable analysis of data collected through RDS.

\section{METHODS}

\section{The OHC study}

The goal of the OHC study was to establish a relevant population health database for urban Indigenous people living in Ontario, through the use of a novel sampling technique and culturally relevant indicators. ${ }^{19}$ The city of Hamilton, Ontario, Canada, was selected as the study site because of its large Indigenous population. According to 2006 census data, 13735 individuals living in Hamilton self-identified as Aboriginal, comprising $2.8 \%$ of the total population. Hamilton is also close to two First Nations reserves: Six Nations of the Grand River and Mississaugas of the New Credit. All data for the OHC survey were collected through a community-based participatory research partnership with the academic research team, the Ontario Federation of Indigenous Friendship Centres and the De Dwa da dehs nye $>$ s Aboriginal Health Centre (DAHAC). These provincial Aboriginal partners were involved with every step of the research process, and research agreements and data management governance 


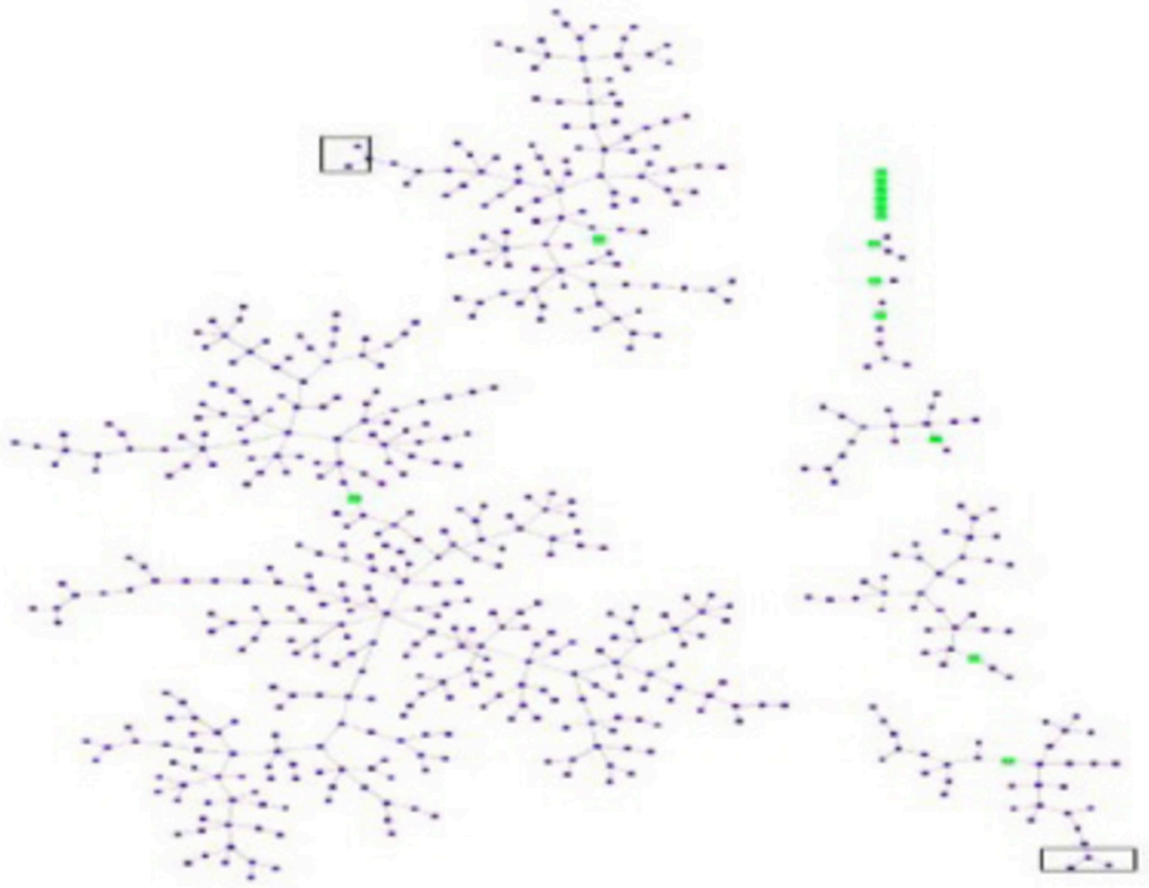

Figure 1 Respondent-driven sampling recruitment tree from the Our Health Counts study. Seeds are indicated in green.

protocols ensured that all Inuit, Métis and First Nations project partners were granted the rights to own, control, have access to and possess all data from the project. ${ }^{19}$ In addition, a governing council of representatives from main partner Aboriginal organisations was established to oversee all stages of the research process, ensure individual and community rights were being respected, address any concerns from the community, and oversee the release of all data from the study. ${ }^{19}$

The OHC survey was designed to be a respectful health assessment, instead of a rapid health assessment, incorporating First Nations health-specific indicators based on cultural and local understandings of health and well-being, as well as questions on health and social issues prioritised by Indigenous stakeholders and community members. The survey was initially piloted to a group of First Nations adults ineligible to participate in the study, who provided feedback on the language used and ways to improve the logical flow of questions. Formal ethics approval for the survey was provided by the Research Ethics Board at St Michael's Hospital (REB \#09-108) in Toronto.

\section{RDS method}

RDS is an effective way to collect data from hidden or hard-to-reach populations that lack sampling frames and cannot be reached using traditional sampling techniques. ${ }^{20-23}$ RDS employs a novel sampling technique to reach these populations utilising peer networks and is capable of generating asymptotically unbiased estimates of population proportions. ${ }^{22}$ In RDS, sample recruitment begins with the non-random selection of initial respondents, or 'seeds', from the target population. ${ }^{22}$ A number of coupons, $k$, are given to each seed, and each seed may then recruit up to $k$ members of the population, who in turn recruit up to $k$ participants and so on. The respondents who are recruited by the seeds make up wave 1 , those recruited by those in wave 1 make up wave 2 , and the process continues with each recruitment making up a distinct node as the chain of referrals grows.

Unlike traditional chain referral sampling methods, such as snowball sampling, RDS can reduce bias that may have been introduced into the sample due to the non-random selection of initial respondents. Moreover, bias due to overvolunteerism can be eliminated by employing a dual incentive system where respondents are rewarded for completing the survey and for every peer they recruit. ${ }^{22}{ }^{23}$ Furthermore, sample size for the OHC survey was determined through a calculation by Salganik, ${ }^{21}$ which estimates that RDS studies should be twice as large as that needed for simple random sampling. Based on this calculation it was determined that a minimum of 500 respondents were needed for the OHC study.

In the OHC study six individuals, selected through the DAHAC, acted as seeds. Of the total respondents in the sample, $78.9 \%$ were recruited through referrals originating from two seeds, with 19 and 32 waves of recruitment, ensuring the composition of the final sample was independent of any bias that may have been introduced with the initial seeds. ${ }^{19}$ Additional seeds were added in February and March of 2010. A copy of the recruitment tree for the OHC study is shown in figure 1.

\section{Recruitment of First Nations participants}

A total of 554 adults completed the OHC survey between December 2009 and April 2010. Eligible participants lived within the city of Hamilton, were at least 18 years of 
Table 1 Demographics of First Nations adults in the Our Health Counts (OHC) study and the city of Hamilton

\begin{tabular}{|c|c|c|c|c|}
\hline & $\begin{array}{l}\text { First Nations adults in } \\
\text { the OHC study (N) }\end{array}$ & $\begin{array}{l}\text { First Nations adults in } \\
\text { the OHC study (\%) }\end{array}$ & City of Hamilton (N) & Hamilton (\%) \\
\hline \multicolumn{5}{|l|}{ Age } \\
\hline $18-34$ & 196 & 37.4 & 125189 & 28.2 \\
\hline $35-49$ & 197 & 37.6 & 124857 & 28.1 \\
\hline $50-64$ & 120 & 22.9 & 110332 & 24.8 \\
\hline $65+$ & 11 & 2.1 & 83829 & 18.9 \\
\hline \multicolumn{5}{|l|}{ Sex } \\
\hline Female & 259 & 49.4 & 226269 & 50.9 \\
\hline Male & 265 & 50.6 & 217938 & 49.1 \\
\hline \multicolumn{5}{|l|}{ Income quartile } \\
\hline Low & 376 & 71.8 & 111468 & 25.1 \\
\hline 2 & 85 & 16.2 & 101200 & 22.8 \\
\hline 3 & 33 & 6.3 & 90069 & 20.3 \\
\hline 4 & 13 & 2.5 & 75704 & 17.0 \\
\hline High & 7 & 1.3 & 65375 & 14.7 \\
\hline Missing & 10 & 1.9 & 391 & 0.1 \\
\hline Total & 524 & & 444207 & \\
\hline Diabetes prevalence & & 15.6 & & 4.9 \\
\hline
\end{tabular}

age and self-identified as First Nations. All surveys were administered by trained Indigenous community surveyors to eligible respondents. Respondents who completed the survey received a financial incentive $(\$ 20)$, as well as $\$ 10$ for every eligible participant they recruited into the study. The recruitment process commenced with six members of the First Nations community in Hamilton who were targeted by the DAHAC and members of the research team. All members attended an information session to learn about the OHC study, and were subsequently given five coupons to distribute to recruit their peers. Demographic information of the adult respondents is provided in table 1, alongside census data from the city of Hamilton.

\section{Analysis}

As there is no standard method for the multivariable analysis of RDS data, two approaches, both grounded in statistical theory, were used to examine the relationship between diabetes and health access barriers of interest. The first approach used weighted logistic regression models, calculated using the function PROC SURVEYLOGISTIC in SAS V.9.4. ${ }^{24}$ Data collected through RDS are complex, ${ }^{20}{ }^{25}$ as recruitment among peers has a tendency to occur in clusters between respondents who are in the same social network and share the same recruiter. ${ }^{23}{ }^{26}$ Furthermore, because RDS relies on social network ties, individuals with larger social networks have an increased likelihood of being recruited into a study, and therefore must be weighted accordingly. ${ }^{23}$ To adjust for correlation, we have adopted a simplified approach that assumes that recruiters (clusters) are nested within trees (strata) to increase the magnitude of the survey-based standard errors. The second approach explored in this analysis was a weighted generalised linear
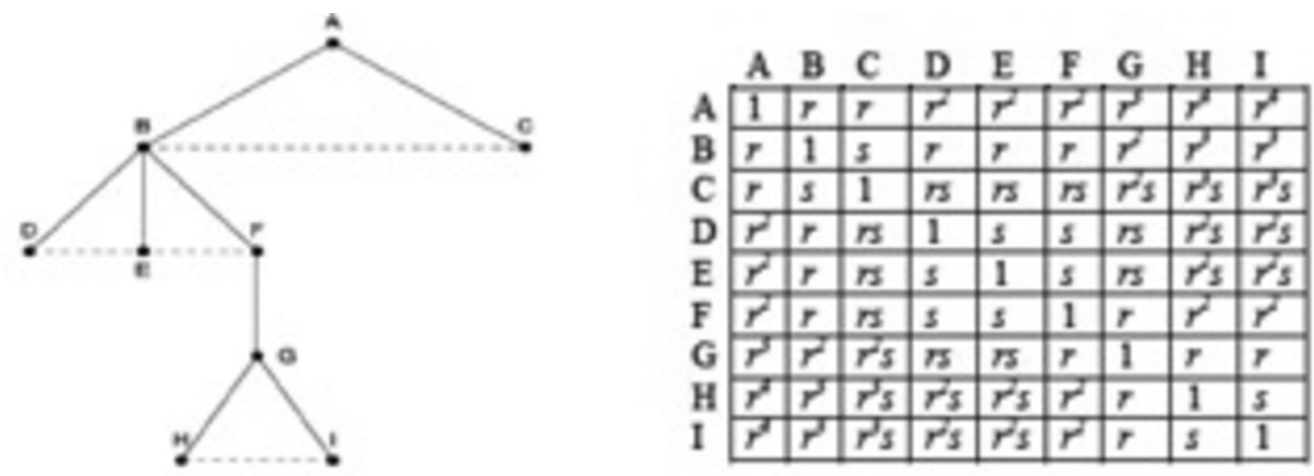

Figure 2 Proposed correlation structure for a single tree in respondent-driven sampling. The $r$ parameter denotes a declining level of correlation throughout the tree (solid line), while s denotes the correlation between participants who are recruited by the same individual (dotted line). 
Table 2 Explanatory variables from the Our Health Counts study survey

\begin{tabular}{|c|c|c|c|}
\hline Variable & Question & Response option & $\begin{array}{l}\text { Survey } \\
\text { question }\end{array}$ \\
\hline $\begin{array}{l}\text { Access to } \\
\text { healthcare }\end{array}$ & $\begin{array}{l}\text { During the past } \\
12 \text { months, have you } \\
\text { experienced any of the } \\
\text { following barriers to } \\
\text { receiving healthcare? }\end{array}$ & $\begin{array}{l}\text { 1. Doctor not available in my area } \\
\text { 2. Nurse not available } \\
\text { 3. Lack of trust in healthcare provider } \\
\text { 4. Waiting list too long } \\
\text { 5. Unable to arrange transportation } \\
\text { 6. Difficulty getting traditional care (ie, healer, medicine person or elder) } \\
\text { 7. Not covered by non-insured health benefits (NIHB) } \\
\text { 8. Prior approval for services under NIHB was declined } \\
\text { 9. Could not afford direct cost of care/service } \\
\text { 10. Could not afford transportation costs } \\
\text { 11. Could not afford childcare costs } \\
\text { 12. Felt healthcare provided was inadequate } \\
\text { 13. Felt service was not culturally appropriate } \\
\text { 14. Chose not to see health professional } \\
\text { 15. Service was not available in my area }\end{array}$ & $\begin{array}{l}\text { Section } \\
\text { 4.C. } 3\end{array}$ \\
\hline $\begin{array}{l}\text { Access to } \\
\text { housing }\end{array}$ & $\begin{array}{l}\text { How many times have } \\
\text { you moved in the past } \\
5 \text { years? }\end{array}$ & Number of times & $\begin{array}{l}\text { Section } \\
\text { 1.B.4 }\end{array}$ \\
\hline Income & $\begin{array}{l}\text { For the year ending } \\
31 \text { December } 2008, \\
\text { please think of your } \\
\text { total personal income, } \\
\text { before deductions, from } \\
\text { all sources. Please look } \\
\text { at these categories and } \\
\text { tell me which range it } \\
\text { falls into: }\end{array}$ & $\begin{array}{l}\text { 1. No personal income } \\
\text { 2. } \$ 1-\$ 4999 \\
\text { 3. } \$ 5000-\$ 9999 \\
\text { 4. } \$ 10000-\$ 14999 \\
\text { 5. } \$ 15000-\$ 19999 \\
\text { 6. } \$ 20000-\$ 24999 \\
\text { 7. } \$ 25000-\$ 29999 \\
\text { 8. } \$ 30000-\$ 39000 \\
\text { 9. } \$ 40000-\$ 49999 \\
\text { 10. } \$ 50000-\$ 59999 \\
\text { 11. } \$ 60000-\$ 69999 \\
\text { 12. } \$ 70000-\$ 79999 \\
\text { 13. } \$ 80000 \text { and over } \\
\text { 14. Don't know } \\
\text { 15. No response }\end{array}$ & $\begin{array}{l}\text { Section } \\
6 . C .1\end{array}$ \\
\hline
\end{tabular}

mixed model, which can account for participant weights and both the fixed effects of study covariates and random effects of correlation. The SAS GLIMMIX procedure was used for this modelling approach. ${ }^{27}$ With generalised linear mixed modelling, identifying the proper covariance structure that best describes the level of correlation between data points is crucial for analysis. ${ }^{28}$ A model of the proposed covariance structure among respondents in the OHC study is proposed in figure $2 .{ }^{29}$ In this model, r corresponds to the correlation of individuals recruited by the same respondent and s accounts for correlation within the same cluster. This proposed covariance structure was used, but sometimes failed to converge due to sparse cells. In this case, a first-order autoregressive covariance structure
(AR[1]) was selected as a replacement given its simplified structure. Similar to figure 2, this structure assumes the magnitude of correlation decreases exponentially with growing distance between observations. ${ }^{30}$ In all models, participants were weighted using RDS-II weights for the outcome. $^{31}$

All access to healthcare variables (table 2) were coded as binary indicators, while a binary variable was created for access to food, comparing having access to enough and the kinds of food you wish to eat (response 1) versus all other categories. The number of moves was dichotomised at two or more moves, while income was coded as an ordinal variable. The presence of diabetes was binary and measured by self-reported physician diagnosis. 
Weighted sex-controlled and age-controlled analyses were completed for each model, followed by models that adjusted for factors that can influence the risk of diabetes, including age, sex, BMI, number of days per week engaging in vigorous physical activity for at least $30 \mathrm{~min}$, alcohol consumption (number of times five or more drinks were consumed in one occasion in the past 12 months) and smoking status (current smoker, former smoker, non-smoker). ${ }^{32} 33$ ORs and their $95 \%$ CIs were generated from each model. The unweighted and unadjusted associations of each health access barrier and diabetes are reported in (online supplementary file 1). Weighted associations that adjusted for age and sex in a simplified adjusted model and a fully adjusted model for age, sex, BMI, physical activity level, alcohol consumption and smoking status are provided. Missing data were minimal with only 10 missing cases for income and were handled by case deletion.

\section{RESULTS}

Table 3 shows the weighted associations between health access barriers and odds of diabetes, after adjusting for sex and age. In the survey logistic regression modelling approach, there was a statistically significant relationship between self-reported diabetes and not being covered by non-insured health benefits (NIHB) (OR 3.66, 95\% CI 1.32 to 10.15 ) and prior approval for coverage under NIHB being denied (OR 3.48, 95\% CI 1.36 to 8.87). In the weighted generalised linear mixed modelling approach, there was a statistically significant relationship between self-reported diabetes and the waiting list to access health services being too long (OR 2.00, 95\% CI 1.19 to 3.38 ), not being covered by NIHB (OR 3.66, 95\% CI 2.00 to 6.70 ), prior approval for coverage under NIHB being denied (OR 3.47, 95\% CI 1.81 to 6.67 ) and income (OR $1.11,95 \%$ CI 1.03 to 1.19 ).

Table 4 shows the weighted associations between health access barriers and odds of diabetes after adjusting for sex, age, BMI, level of physical activity, alcohol consumption and smoking status. In the survey logistic regression modelling approach, a statistically significant relationship was found between self-reported diabetes and feeling that healthcare provided was inadequate (OR 8.54, 95\% CI 1.40 to 53.40), respondents feeling healthcare provided was not culturally appropriate (OR $17.87,95 \%$ CI 2.90 to 110.24 ) and income (OR 1.29, 95\% CI 1.03 to 1.63). Using the weighted generalised linear mixed methods model approach, feeling that health services were not culturally appropriate was significantly associated with self-reported diabetes (OR 12.70, 95\% CI 2.52 to 57.91). The health access barriers of not being able to afford childcare costs and choosing not to see a health professional failed to converge in the generalised linear mixed methods model due to sparse cells.

\section{DISCUSSION}

After adjusting for covariates, our results indicate a greater likelihood of urban First Nations adults with diabetes experiencing barriers to culturally appropriate health services, compared with those who do not have

\begin{tabular}{|c|c|c|}
\hline Health access variables adjusted for sex and age & Surveylogistic & Glimmix \\
\hline & OR $(95 \% \mathrm{Cl})$ & OR $(95 \% \mathrm{Cl})$ \\
\hline Doctor not available in my area & 0.94 (0.38 to 2.31$)$ & $0.96(0.53$ to 1.74$)$ \\
\hline Nurse not available & $1.14(0.42$ to 3.10$)$ & 1.17 (0.59 to 2.30$)$ \\
\hline Lack of trust in healthcare provider & $1.45(0.64$ to 3.30$)$ & $1.47(0.78$ to 2.70$)$ \\
\hline Waiting list too long & $1.97(0.87$ to 4.48$)$ & 2.00 (1.19 to 3.38$)$ \\
\hline Unable to arrange transportation & 1.29 (0.54 to 3.09$)$ & $1.27(0.74$ to 2.19$)$ \\
\hline Difficultly getting traditional care (ie, healer, medicine person or elder) & $0.62(0.24$ to 1.64$)$ & $0.62(0.28$ to 1.35$)$ \\
\hline Not covered by non-insured health benefits (ie, service, medication, equipment) & $3.66(1.32$ to 10.15$)$ & $3.66(2.00$ to 6.70$)$ \\
\hline Prior approval for services under non-insured health benefits denied & $3.48(1.36$ to 8.87$)$ & 3.47 (1.81 to 6.67$)$ \\
\hline Could not afford direct cost of care/service & 1.74 (0.67 to 4.53$)$ & $1.72(0.98$ to 3.01$)$ \\
\hline Could not afford transportation costs & 1.19 (0.50 to 2.83$)$ & 1.20 (0.69 to 2.07$)$ \\
\hline Could not afford childcare costs & 1.03 (0.33 to 3.19$)$ & 1.10 (0.34 to 3.58$)$ \\
\hline Felt healthcare provided was inadequate & $1.16(0.46$ to 3.00$)$ & $1.16(0.65$ to 2.05$)$ \\
\hline Felt service was not culturally appropriate & $1.26(0.48$ to 3.29$)$ & 1.24 (0.67 to 2.27$)$ \\
\hline Chose not to see health professional & 1.17 (0.49 to 2.77$)$ & 1.18 (0.67 to 2.10$)$ \\
\hline Service was not available in my area & $1.62(0.69$ to 3.80$)$ & 1.55 (0.82 to 2.91$)$ \\
\hline Access to food in the last 12 months & $0.83(0.51$ to 1.34$)$ & $0.85(0.65$ to 1.11$)$ \\
\hline Income & 1.10 (0.97 to 1.24$)$ & $1.11(1.03$ to 1.19$)$ \\
\hline Access to housing & 1.01 (0.97 to 1.06$)$ & 1.01 (0.97 to 1.06$)$ \\
\hline
\end{tabular}


Table 4 Weighted analysis of association between health access barriers and diabetes, adjusted for sex, age, body mass index (BMI), physical activity level, smoking status and alcohol habits

\begin{tabular}{|c|c|c|}
\hline $\begin{array}{l}\text { Health access variables adjusted for sex, age, physical activity level, BMI, } \\
\text { alcohol use and smoking status }\end{array}$ & Surveylogistic & Glimmix \\
\hline & OR $(95 \% \mathrm{Cl})$ & OR $(95 \% \mathrm{Cl})$ \\
\hline Doctor not available in my area & $4.06(0.93$ to 17.77$)$ & 4.07 (0.98 to 16.84$)$ \\
\hline Nurse not available & $0.76(0.08$ to 6.86$)$ & $0.79(0.13$ to 4.77$)$ \\
\hline Lack of trust in healthcare provider & 2.05 (0.34 to 12.36$)$ & $2.11(0.48$ to 9.21$)$ \\
\hline Waiting list too long & $3.50(0.69$ to 17.71$)$ & $3.43(0.62$ to 18.86$)$ \\
\hline Unable to arrange transportation & $3.98(0.81$ to 19.44$)$ & 4.02 (0.68 to 23.67$)$ \\
\hline Difficultly getting traditional care (ie, healer, medicine person or elder) & $7.91(0.76$ to 82.14$)$ & $7.92(0.50$ to 124.63$)$ \\
\hline Not covered by non-insured health benefits (ie, service, medication, equipment) & $1.46(0.38$ to 5.61$)$ & $1.64(0.36$ to 7.49$)$ \\
\hline Prior approval for services under non-insured health benefits denied & $1.14(0.19$ to 6.77$)$ & $1.14(0.22$ to 5.83$)$ \\
\hline Could not afford direct cost of care/service & $1.69(0.27$ to 10.57$)$ & 1.85 (0.35 to 9.82$)$ \\
\hline Could not afford transportation costs & $0.54(0.07$ to 4.03$)$ & $0.48(0.06$ to 3.76$)$ \\
\hline Could not afford childcare costs & $<0.001$ & - \\
\hline Felt healthcare provided was inadequate & $8.54(1.40$ to 53.40$)$ & 8.19 (0.97 to 69.31$)$ \\
\hline Felt service was not culturally appropriate & $17.87(2.90$ to 110.24$)$ & $12.07(2.52$ to 57.91$)$ \\
\hline Chose not to see health professional & $3.41(0.64$ to 18.30$)$ & - \\
\hline Service was not available in my area & $7.60(0.89$ to 65.15$)$ & 7.46 (0.97 to 57.45$)$ \\
\hline Access to food in the last 12 months & 0.38 (0.09 to 1.59$)$ & 0.38 (0.10 to 1.40$)$ \\
\hline Income & 1.29 (1.03 to 1.63$)$ & 1.30 (0.98 to 1.72$)$ \\
\hline Access to housing & $0.52(0.26$ to 1.07$)$ & $0.53(0.18$ to 1.55$)$ \\
\hline
\end{tabular}

diabetes. Culturally appropriate care considers the differences between cultural concepts of health and the biomedical perceptions of health and creates a space where the cultural beliefs of the patient utilising the services are being respected. ${ }^{34}$ This can mean the use of a local language, the use of local knowledge on healing in combination with Western medicine in a patient's care plan, or involving members of the local community in the planning and delivery of healthcare. ${ }^{35}$ Culturally appropriate care recognises that culture can influence one's perceptions of illness, including coping mechanisms and the willingness to seek treatment. ${ }^{35}$ Establishing services that are culturally appropriate is one of the first steps in achieving truly comprehensive care for all populations. ${ }^{35}$ The next step is implementing culturally competent care, which should recognise inequitable access to healthcare and requires health services and providers to adapt to meet the cultural, social and linguistic needs of all patients. ${ }^{36}$ The Truth and Reconciliation Commission of Canada recently put forward a recommendation that all healthcare professionals receive cultural competency training, ${ }^{37}$ and in response to this the province of Ontario has made cultural competency training mandatory for all public service employees. ${ }^{38}$ The final step should be the implementation of cultural safety, a conceptual framework distinct from the other concepts in that it addresses the diverse health needs of Indigenous peoples, as well as the unequal power dynamic that exists between a healthcare provider and a service user, and how this power imbalance can negatively influence a person's healthcare experience. ${ }^{39} 40$ Culturally safe care begins when healthcare providers reflect on their own privileges and culture, and how these can marginalise patients with a different culture, on which the provider can then initiate a collaborative exchange of health information with the service user that is not demeaning or disrespectful. ${ }^{39-41}$ The inability of mainstream healthcare providers to address the diverse health needs of Indigenous patients could be resolved by implementing a healthcare environment that is culturally safe, which could provide Indigenous patients greater control over their care, potentially translating into higher rates of compliance and better long-term health outcomes. ${ }^{41}$ The findings in this paper align with recent qualitative research on Indigenous experiences with healthcare in Canada, which found Indigenous peoples still incur racism, discrimination and stereotyping when accessing health services in both urban and rural settings. ${ }^{42}$ More concerted efforts to train healthcare professionals on enhancing their patient-centred approaches to care, developing health programmes that put a greater emphasis on a holistic view of human health and involving local communities in the development of health-related policies has the potential to enhance the healthcare experience for Indigenous people in Canada. ${ }^{1642}$

Jurisdictional discrepancies in healthcare coverage further inhibit accessibility to health services for Indigenous peoples living in urban spaces in Canada. In 
this paper, there was evidence of a significant association between urban First Nations adults with diabetes and having a new or existing application for the NIHB programme denied in the partially adjusted models. The Federal Government of Canada funds the NIHB programme, which provides additional coverage of medical services and goods not accessible through private plans or provincial programmes, to eligible First Nations and Inuit peoples. ${ }^{43}$ To be eligible for the NIHB programme, a person needs to be a First Nations person with status or an Inuit person. ${ }^{343}$ Métis and non-status First Nations peoples are excluded from the NIHB programme, despite facing the same health disparities as other Indigenous peoples in Canada. ${ }^{3}$ Furthermore, a number of the services offered by the NIHB programme are limited to First Nations peoples living on reserves only, limiting the number of services available to First Nations peoples who move off reserve. ${ }^{3}$

One limitation of this paper is that the data collected are cross-sectional; therefore, causality cannot be established. On initial review of the data, it could be inferred that the lack of access to culturally appropriate health services may contribute to increased prevalence of diabetes; however, this could be an example of bias by indication where those individuals with diabetes are seeking out medical care more often and are therefore more likely to find these health services less culturally appropriate. Even though causality cannot be inferred, a significant association between individuals with diabetes and the need for more culturally appropriate health services has been shown. Furthermore, because the presence of diabetes had to be confirmed from a healthcare professional, and this study population underuses health services, the prevalence of diabetes may have been under-reported. Another limitation is the lack of a standardised method for regression modelling using data collected through RDS. Preliminary simulation studies are underway and show that both approaches reasonably maintain their type 1 error rate; however, more research is needed prior to making general recommendations. A strength of this study is the use of RDS to recruit urban First Nations peoples, thus allowing for a more valid representation of the urban First Nations community in the city of Hamilton. Moreover, although some variables did not meet the traditional levels of statistical significance in the fully adjusted models, there is still evidence of very large effect sizes, illustrating the potential impact of these variables.

The unique sampling design of the OHC study provides a valid and asymptotically unbiased representation of the growing urban First Nations community. Using data collected through the OHC study, the results from this paper indicate a need for more culturally appropriate health services in urban areas as an imminent first step to improve health access and potentially reduce the rate of diabetes in this population. The findings of this paper warrant further exploration into the importance of cultural safety as a social determinant for Indigenous health, particularly for First Nations peoples living in an urban environment.
Contributors JS, MAF, CDM and MAR reviewed and edited the manuscript and provided thoughtful feedback. MB wrote the manuscript. MAR designed and reviewed the statistical analysis plan and critically reviewed the manuscript. All authors approved the final version of this manuscript. MB is the guarantor of this work, and as such had full access to all the data in the study and takes responsibility for the integrity of the data and the accuracy of the data analysis.

Funding This paper was supported by Grant 133703 from the Canadian Institute for Health Research.

Disclaimer The funders had no role in the study design, data collection and analysis, decision to publish, or preparation of the manuscript.

Competing interests None declared.

Patient consent Not required.

Ethics approval St Michael's Hospital Research Ethics Board.

Provenance and peer review Not commissioned; externally peer reviewed.

Data sharing statement All data are owned and managed by our Indigenous community partners. Due to data sharing and ethics agreements, access to this data set cannot be provided.

Open Access This is an Open Access article distributed in accordance with the Creative Commons Attribution Non Commercial (CC BY-NC 4.0) license, which permits others to distribute, remix, adapt, build upon this work non-commercially, and license their derivative works on different terms, provided the original work is properly cited and the use is non-commercial. See: http://creativecommons.org/ licenses/by-nc/4.0/

(c) Article author(s) (or their employer(s) unless otherwise stated in the text of the article) 2018. All rights reserved. No commercial use is permitted unless otherwise expressly granted.

\section{REFERENCES}

1. Canada S. Aboriginal Peoples in Canada in 2006: Inuit, Métis and First Nations, 2006 Census. Ottawa, ON: Minister of Industry, 2008.

2. Canada S. Aboriginal Peoples in Canada: First Nations people, Inuit and Métis, 2011 National Household Survey. Ottawa, ON: Minister of Industry, 2016.

3. Allan B, Smylie J, Peoples F. second-class treatment: The role of racism in the health and well-being of Indigenous peoples in Canada. Toronto: The Wellesley Institute, 2015.

4. Report on the Royal Commission of Aboriginal Peoples. Ottawa, ON: Indian and Northern Affairs, 1996.

5. Browne AJ, Smye VL, Rodney P, et al. Access to primary care from the perspective of Aboriginal patients at an urban emergency department. Qual Health Res 2011;21:333-48.

6. Norris M, Clatworthy S. Aboriginal mobility and migration in urban canada: outcomes, factors and implications. In: Newhouse D, Peters $\mathrm{E}$, eds. Not strangers in these parts: Urban Aboriginal peoples. Ottawa, ON: Policy Research Initiative, 2003:51-79.

7. Tjepkema M, Wilkins R, Senécal S, et al. Mortality of urban Aboriginal adults in Canada, 1991-2001. Chronic Dis Can 2010;31:4-21.

8. Norris MJ, Clatworthy S. Urbanization and migration patterns of aboriginal populations in canada: a half century in Review (1951 to 2006). Aboriginal policy studies 2011;1:13-77.

9. Smylie J, Adomako P. Indigenous Children's Health Report: health assessment in action. Toronto: Centre for Research on Inner City Health, 2009.

10. Anderson M, Smylie J, Anderson I, et al. First Nations, Métis and Inuit Health Indicators in Canada: a background paper for the project "Action oriented indicators of health and health system development for Indigenous peoples in Canada, Australia and New Zealand.". Saskatoon: Indigenous Peoples' Health Research Centre, 2006. www.iphrc.ca/text/canadian.pdf. (accessed 15 Jun 2015).

11. Smylie J, Firestone M. Back to the basics: Identifying and addressing underlying challenges in achieving high quality and relevant health statistics for Indigenous populations in Canada. Stat J IAOS 2015;31:67-87.

12. Senese LC, Wilson K. Aboriginal urbanization and rights in Canada: examining implications for health. Soc Sci Med 2013;91:219-28.

13. Reading J. The Crisis of Chronic Disease among Aboriginal Peoples: a challenge for public health, population health and social policy. Centre for Aboriginal Health Research 2009.

14. Harris SB, Bhattacharyya O, Dyck R, et al. Type 2 diabetes in Aboriginal peoples. Can J Diabetes 2013;37 (Suppl 1):S191-196. 
15. Canadian Community Health Survey. Diabetes in Canada: facts and figures from a Public Health Perspective, 2009-2010 Canadian Community Health Survey. Ottawa ON: Public Health Agency of Canada, 2011. (accessed 23 Dec 2016).

16. Ghosh H, Spitzer D. Inequities in diabetes outcomes among urban First Nation and Métis communities: can addressing diversities in preventive services make a difference? Int Indij Policy J 2014;5:1-26

17. Bombay A, Matheson $\mathrm{K}$, Anisman $\mathrm{H}$. The intergenerational effects of Indian Residential Schools: implications for the concept of historical trauma. Transcult Psychiatry 2014;51:320-38.

18. Leung L. Diabetes mellitus and the Aboriginal diabetic initiative in Canada: an update review. J Family Med Prim Care 2016;5:259.

19. Smylie J, Firestone F, Cochran L, et al. Our health counts. Urban Aboriginal Health Database Research Project. Community Report: First Nations Adults and Children. Toronto: Centre for Research on Inner City Health, 2011.

20. Heckathorn DD. Respondent-driven sampling: a new approach to the study of hidden populations. Soc Probl 1997;44:174-99.

21. Salganik MJ. Variance estimation, design effects, and sample size calculations for respondent-driven sampling. J Urban Health 2006;83:98-112.

22. Heckathorn DD. Respondent-driven sampling II: deriving valid population estimates from chain-referral samples of hidden populations. Soc Probl 2002;49:11-34.

23. Salganik MJ, Heckathorn DD. Sampling and estimation in hidden populations using respondent-driven sampling. Sociol Methodol 2004;34:193-240.

24. SAS Institute. SAS/STAT 9.2 User's Guide: the SURVEYLOGISTIC Procedure (book excerpt). Cary, NC: SAS Institute Incorporated, 2012.

25. Oyeyemi GM, Adewara AA, Adeyemi RA. Complex Survey Data Analysis: A Comparison of SAS, SPSS and STATA. Asian J Math Statistics 2010;3:33-9.

26. Wears RL. Advanced statistics: statistical methods for analyzing cluster and cluster-randomized data. Acad Emerg Med 2002;9:330-41.

27. SAS Institute. SAS/STAT 9.2 user's guide: the GLIMMIX procedure (book excerpt). Cary, NC: SAS Institute Incorporated, 2012.

28. Barnett A, Koper N, Dobso A, et al. Selecting the correct variancecovariance structure for longitudinal data in ecology: a comparison of the akaike, quasi-information and deviance information criteria. Methods Ecol Eval 2009;1:15-24.
29. Rotondi M. Aboriginal Health Counts: advancing multivariable methods for respondent driven sampling. York University prepared for the Canadian Institute for Health Research Grant number 133703 Sept. 2013.

30. Hilbe J. Generalized modellinear. Am Stat 1994;48:255-65.

31. Volz E, Heckathorn D. Probability based estimation theory for respondent-driven sampling. J Off Stat 2008;24:79-97.

32. Shield K, Parry C, Rehm J. Chronic diseases and conditions related to alcohol use. Alcohol Res 2014;35:155-71.

33. World Health Organization. Diabetes Fact sheet, 2017.

34. DeVerteuil G, Wilson K. Reconciling indigenous need with the urban welfare state? Evidence of culturally-appropriate services and spaces for Aboriginals in Winnipeg, Canada. Geoforum 2010;41:498-507.

35. National Collaborating Centre for Aboriginal Health. Culture and language as Social Determinants of First Nations, Inuit and Métis Health. Prince George, BC: National Collaborating Centre for Aboriginal Health, 2010.

36. National Collaborating Centre for Aboriginal Health. Towards cultural safety for Métis: an introduction for health care providers. Prince George, BC: National Collaborating Centre for Aboriginal Health, 2013.

37. Truth and Reconciliation Commission of Canada. Truth and Reconciliation Commission of Canada: calls to action. Winnipeg: Truth and Reconciliation Committee, 2015.

38. Leslie K. Ontario pledges $\$ 100$ million to help end violence against Indigenous women.CBC [internet]. $2016 \mathrm{http}: / / w w w . c b c . c a / n e w s /$ aboriginal/ontario-pledges-100million-to-help-end-violence-againstindigenous-women-1.3459951 (Cited 6 Mar 2016).

39. Brascoupé $\mathrm{S}$, Waters $\mathrm{C}$. Cultural safety: exploring the applicability of the concept of cultural safety to Aboriginal health and community wellness. Int J Indig Health 2009;5:6-41.

40. National Aboriginal Health Organization. Cultural competency and safety: a guide for health care administrators, providers and educators. Ottawa: National Aboriginal Health Organization, 2008.

41. National Collaborating Centre for Aboriginal Health. Cultural safety in healthcare. Prince George, BC: National Collaborating Centre for Aboriginal Health, 2013.

42. Jacklin KM, Henderson RI, Green ME, et al. Health care experiences of Indigenous people living with type 2 diabetes in Canada. CMAJ 2017; 189:E106-12.

43. First Nations and Inuit Health. Ottawa: Health Canada, 2016. http:// www.hc-sc.gc.ca/fniah-spnia/nihb-ssna/index-eng.php. (accessed 01 May 2016). 